\title{
Performance Characteristics of Hedge Fund Indices
}

\author{
Sheeba Kapil1 ${ }^{1}$ Jayesh Gupta ${ }^{2}$ \\ ${ }^{1}$ Department of Finance, Indian Institute of Foreign Trade, New Delhi, India \\ ${ }^{2} \mathrm{~J}$ M Financial, New Delhi, India \\ Email: sheebakapil@iift.edu, jayeshgupta17@yahoo.com
}

How to cite this paper: Kapil, S. and Gupta, J. (2019) Performance Characteristics of Hedge Fund Indices. Theoretical Economics Letters, 9, 2176-2197. https://doi.org/10.4236/tel.2019.96138

Received: June 25, 2019

Accepted: August 27, 2019

Published: August 30, 2019

Copyright $\odot 2019$ by author(s) and Scientific Research Publishing Inc. This work is licensed under the Creative Commons Attribution International License (CC BY 4.0).

http://creativecommons.org/licenses/by/4.0/

\section{c) (i) Open Access}

\begin{abstract}
The focus of the study is to provide a detailed account of how various strategy-specific or composite hedge fund indices have performed in the past. The study analyses returns (monthly) of different hedge funds. The study selected popular categories of Hedge fund index against DJIA (Dow Jones Industrial Average) and Credit Suisse Hedge Fund Index. The Data is taken from January 1994 to December 2018 and is taken from Credit Suisse Hedge fund database. The study finds that most hedge fund indices witness a drop in returns over time, and most hedge funds do not provide additional diversification benefits with respect to traditional asset class. On a risk-adjusted basis, majority of hedge fund indices out-perform the broader equity market, risk-adjusted performances of various hedge fund strategies, does not change drastically with use of different risk-adjusted measures. As opposed to prevalent studies like Atil, Bali and Demirtas [1] [2], indicating Equity market neutral hedge fund index as the best performer in terms of risk-adjusted returns, the current study finds Event Driven Distressed hedge fund Index as the best performer.
\end{abstract}

\section{Keywords}

Hedge Funds, Calmar Ratio, Sharpe Ratio, Sortino Ratio, Drawdown, Risk-Adjusted Return

\section{Introduction}

A Hedge Fund is an unregulated mutual fund and charges fee as rule of 2 and 20. It refers to a typical fee arrangement of hedge funds where the annual management fee of $2 \%$ and profit sharing fee of $20 \%$. Alfred Winslow Jones was the first hedge fund manager, with his first for profit hedge fund. He charged perfor- 
mance linked fees (20\% of profit) but no asset management fee. He combined long positions in undervalued stocks and short positions in overvalued ones. This allowed him to make at least a small net profit in every market condition, while reducing the overall risk through a smaller net market exposure.

This study aims to analyze risk and return of select top hedge funds indices (as per their Asset under management-AUM) along with that of market index. This study is aimed at analysing the risk-adjusted performance of various strategy-specific and composite hedge fund indices.

\section{Review of Literature}

Hedge fund as defined by Goldman Sachs \& Co is: "A multitude of skill-based investment strategies with a broad range of risk and return objectives. A common element is the use of investment and risk management skills to seek positive returns regardless of market direction" [3] [4].

Hedge funds performance is normally driven by active management decisions (the "alpha") rather than from passively holding of asset class and deriving the risk premium (the "beta"). This also implies that hedge funds have flexible investment policies. Another common feature of hedge fund is less stringent regulatory framework surrounding them. Many hedge funds are registered at off shore tax-havens. Also, there is very low transparency in their operations. Less transparency is desirable for Hedge funds as they would not want outsiders to know about their strategic positions and specific short sell.

The collapse of the long-term capital management in 1997 and the liquidation of several hedge funds over the last few years have left many investors demanding a better understanding of the hedge funds investment strategies. On the one hand, researchers argue that hedge funds strategies dominate mutual funds strategies and provide a more efficient investment opportunity set for investors [5]. On the other hand, the common perception in the general public is that hedge fund investments are extremely risky and their operations are totally lack of transparency. While in extreme cases operational risk events can lead to fund failure, Brown et al. [6] show that operational risk associated with conflicts of interest both within the fund and external to the fund can lead to a reduction in return of on average of 1.68 percent on an annualized basis. Because their trading strategies are considered proprietary and not disclosed to the investors, it is even more challenging to make a risk assessment.

Fung and Hsieh [7] [8] first reported that the returns of hedge funds typically have low correlation to standard asset indices. Documented more extensively in Schneeweis and Spurgin [9] [10], these results have been confirmed in all subsequent studies. A second set of results, reported in Fung and Hsieh [7] and verified in Brown, Goetzmann, and Ibbotson [11] and Brown, Goetzmann, and Park [5], quantitatively showed that there are many hedge fund styles, each exhibiting different return characteristics.

In addition, Fung and Hsieh [7] [8] found evidence that some of these styles 
can generate option-like return. Hedge funds are "zero-beta like" investments. While zero-beta securities have no systematic risk [12], it is well known that they have absolute risk. Hedge fund failures have occurred in companies with event risk in their trading styles [13]. A case in point is Long-Term Capital Management (LTCM) [14] in Greenwich, CT. Until mid-1998, LTCM's returns had low correlation with any of the major asset markets and a standard deviation comparable to that of the S\&P 500 index. While LTCM had low systematic and absolute risk as measured by conventional methods, it, nonetheless, had significantly high risk as evident in 1998 the year of LTCM collapse.

Some research is also available on mutual funds and to the hedge fund setting by studying a broad set of exotic risks not typically available through mutual funds [15]. Investors face considerably greater model uncertainty when evaluating hedge fund performance and we explore whether investors learn over time as they become more informed about the types of risk exposures that hedge funds seek out [16]. Some empirical evidence reveals that during the recent financial crisis, the returns from providing liquidity increased and the stocks traded by hedge funds that used Lehman Brothers as prime broker became less liquid, which indirectly suggests that hedge funds withdrew from the market [5].

Performance into traditional and exotic risk components and find that while investors chase both components, they place greater relative emphasis on returns associated with exotic risk exposures that can only be obtained through hedge funds [17]. However, we find little evidence of persistence in performance from traditional or exotic risks, which suggests investors should adjust for these risks when evaluating fund performance rather than seeking them out following periods of success.

Schmidhuber and Moix [18] emphasized the nature of hedge fund returns and stated that hedge fund returns are not normally distributed and may be better represented by a hyperbolic distribution. They show skewness and kurtosis. This is because hedge funds rely on alpha and create absolute return. They protect the invested capital through hedging strategies and particular investment styles induce asymmetric return distributions or diversifying with commodities [19]. Hedge fund investors act like arbitrageurs and engage in sophisticated trading strategies, use leverage, and take short positions [20]. In spite of being unregulated they still get monitored by investors due to outside financing, which may curtail their ability to exploit profit opportunities. Limits on hedge funds' arbitrage potential are likely to be more severe during market crises like that of 2007-08. At such times, in response to initial losses, capital providers, investors, and lenders may withdraw their funds and force the hedge funds to liquidate their positions. While Agarwal, Daniel, and Naik [21] show that successful hedge funds receive capital inflows, however investors react differently to distinct components of fund returns.

Many hedge funds are exposed to aggregate equity market risk, including putatively "market neutral" funds. Building on Fung and Hsieh [7] develop unique 
trend-following risk factors for hedge fund styles that pursue dynamic strategies, while Fung and Hsieh [7] [8] propose a broad array of asset-based style factors to account for the manifold risks faced by different hedge fund styles. Other studies analyzing relevant risk factors for hedge funds include Mitchell and Pulvino [20], Agarwal and Naik [21] [22].

The usual performance metric is the eponymous Sharpe ratio established in Sharpe [23]. It is a simple number easy to derive and intuitive to understand as it computes the ratio of the excess return over the strategy standard deviation. It has various limitations that have been widely emphasized by various authors, Sharpe leading to other performance ratios like Treynor ratio [24], but also Calmar, Sterling or Burke ratio.

Several risk measures which were based on estimation of covariance matrices using historical data failed when they are needed the most. They agreed that the difference in volatility and correlations between up and down market environments implies the risk reduction potential is limited leaving them incapable of foreseeing stress-type events. It is understood that large drawdowns usually lead to fund redemption, and hence they lead to very different optimal decisions. Magdon-Ismail, Atiya, Pratap [25] provided a statistically coherent downside risk measure, the Calmar ratio with the expected maximum drawdown, which provides a theoretical base for this study to apply this downside risk measure as a differentiable objective function. Calmar ratio is distinctly different from the exponential moving average drawdown approach.

Recently with advent of cryptocurrency usage and underlying block chain algorithm several hedge funds floated cryptocurrency hedge funds. The performance of the cryptocurrency hedge funds has been not very encouraging. As world faced Greece crisis and Brexit it witnessed decline in value of all traded cryptocurrencies, both for the flagship Bitcoin as well as for its alternatives (the altcoins). By the end of the first quarter of 2018, high volatility, and downward momentum of cryptocurrencies, led to the closure of many hedge funds. The average performance of crypto hedge funds was around $-20 \%$ returns YTD (year-to-date), and this sort of haemorrhaging loss has meant that roughly ten different crypto hedge funds have reported that they are ceasing, or have already ceased, their operations. According to the Crypto-Currency Hedge Fund Index, constructed by Eurekahedge, the average performance of crypto hedge funds in 2018 has been a loss of $-23.31 \%$ as of March, with February having ended in a monthly loss of $-18.75 \%{ }^{1}$.

In Risk measurement of hedge funds sharpe ratio is a common ratio used by researchers. Sharpe ratio, assumes that the standard deviation of the return distribution provides the full description of risk. In reality, investors are risk averse. They do not want negative returns and huge draw downs. The asymmetric behaviour of risk is not truly captured by Sharpe ratio which may be "gamed" us${ }^{1}$ Chohan, Usman W., Cryptocurrency Hedge Fund Performance: Risks and Challenges (April 4, 2018). Available at SSRN: https://ssrn.com/abstract $=3156891$ or http://dx.doi.org/10.2139/ssrn.3156891. 
ing simple derivative strategies. As an alternative the Sortino ratio has been advocated in order to capture the asymmetry of the return distribution [26] [27]. It replaces the standard deviation in the Sharpe ratio by the downside deviation which captures only the downside risk.

Hedge funds invest in various investment styles. Each investment style becomes hedge fund strategy and an index. All hedge fund strategies aim at maximizing alpha. Despite the various hedge fund strategies, one question remains pertinent: Are Hedge funds superior performers? Many studies suggest superiority for the hedge funds, while there are equal number of studies arguing otherwise. However, Ackermann, McEnally, and Ravenscraft [1] argue that the 2 plus 20 incentive structure of hedge funds has ensured that the average Sharpe ratio of Hedge funds is higher than mutual funds. Also, Jagannathan, Malakov, and Novikov [28] [29] argue that the return of hedge funds is driven by top performers, supported by the rigorous recruitment done by the Hedge fund industry.

Further, studies by Amin and Kat [30] argue that hedge fund are not superior performers and their benefits only accrue to an investor, when hedge funds are a part of the investor's portfolio, given the weak correlation with market indices. Also, some studies argue that the return to a hedge fund investor is also dependent upon the entry exit timing and the quantum of fund inflow. Such line of argument is supported by Dichev and Yu [31]. Another important aspect of hedge fund industry is the illiquidity arising from lock-up period and share restrictions. As per Aragon [32] [33], the abnormal return of fund of fund with a lock up period is significantly higher than funds, which allow easy redemption for their investors.

The focus of this paper is performance measurement of hedge fund with special focus on risk adjusted performance. The paper uses different risk measures like standard deviation, semi-deviation and drawdown to adequately understand various dimensions of investment risk and return [34] [35].

\section{Data and Methodology}

\subsection{Data Source}

Data of selected hedge fund indices are taken from time period, January 1994 to December 2017. The data source is Credit Suisse Hedge fund database. Hedge fund data unlike mutual fund data is not a random sample of the entire universe as hedge funds may choose to not report their performance ${ }^{2}$.

\subsection{Return and Risk Characteristics Measures}

The normal return and risk measures used in the study are mean, Standard deviation, median, skewness, and kurtosis. The risk adjusted return $\mathrm{s}$ is measured with Calmar ratio, Sortino ratio and Sharpe ratio. So the returns (monthly) of different categories of Hedge fund were analysed against DJIA (Dow Jones In${ }^{2}$ Further, Hedge fund data exposed to survivorship bias, as some hedge funds are excluded from hedge fund index as they are no longer alive. 
dustrial Average) and Credit Suisse Hedge Fund Index. These ratios are called safety first risk measures. The Sharpe ratio is widely used and it was developed based on mean-variance optimization; therefore, its risk measure is the standard deviation of returns.

The Sortino ratio uses the downside deviation and it includes a target for the investment return. Sortino ratio implicitly states that the semi deviation is the appropriate measure of risk. Sortino ratio neither (necessarily) calculates excess returns with respect to the risk-free rate nor (necessarily) calculates risk with respect to the mean. Differences exist between standard deviation and semi deviation which implies that the perceived risk (and as a result the risk-adjusted return) of an asset depends on which of these two magnitudes is used to assess it. The Sortino ratio uses the downside deviation and it includes a target for the investment return.

Calmar ratio includes the expected maximum drawdown. The Calmar ratio is a comparison of the average annual compounded rate of return and the maximum drawdown risk. Calmar is the ratio of the annualized excess return and maximum drawdown. Calmar ratio includes the expected maximum drawdown. The Calmar ratio (CR) is similar to the Sharpe ratio (SR) in that it is also a risk-adjusted measure of performance. However, it is an MDD risk metric that measures the maximum cumulative loss from a peak to a following bottom. When the downside losses are considered rather than the average deviation from mean return, the trading decisions will certainly be different. Here the study derives reward based on this E (MDD) risk-based measure, the Calmar ratio. The Calmar ratio is defined as using the expected maximum drawdown because it is consistent, coherent and differentiable by definition as it can be seen from the definition of the expected maximum drawdown. The drawdown of a fund measures the loss incurred over a given investment period. As Exhibit 1 shows, the Calmar, Sterling, and Burke ratios use as risk measures, respectively, the maximum drawdown, an average of a certain number of drawdowns, and a type of standard deviation of a number of the largest drawdown.

Investors think of risk differently from the way it is defined in modern portfolio theory. Both the standard deviation and beta give equal weight to upside and downside fluctuations. It is perhaps for this reason that the downside risk framework has been rapidly gaining acceptance among academics and practitioners. Semideviation exhibits several interesting characteristics as a measure of risk. It captures the downside volatility that investors want to avoid and not the upside volatility investors are seeking. It assesses risk just as well as standard deviation when the underlying distribution of returns is symmetric and the benchmark is the mean, and it does a better job when this distribution is skewed or the benchmark is any return other than the mean. And it summarizes in a single number the relevant information provided by two parameters, the standard deviation and the coefficient of skewness. The downside beta isolates the downside potential of an asset's returns relative to that of the market's returns. According to this measure, 
assets that magnify the market's upward swings are not necessarily risky; only those that magnify the market's downward swings are. Both the semideviation and the downside beta are easy to estimate and can be calculated in just one cell in Excel. Among many other uses, they can be used to estimate required returns on equity and to assess risk-adjusted returns. And as the data from the few companies considered shows, the differences between required returns on equity based on the CAPM and those based on downside risk can be substantia.

\subsection{Hedge Funds Database}

In this appear the top hedge funds were selected based on their value as given below:

- Convertible Arbitrage Hedge Fund;

- Dedicated Short Bias Hedge Fund;

- Long/Short Equity Hedge Fund;

- Emerging Markets Hedge Fund;

- Equity Market Neutral Hedge Fund;

- Event Driven Hedge Fund;

- Event Driven Distressed Hedge Fund;

- Event Driven Multi-Strategy Hedge Fund;

- Fixed Income Arbitrage Hedge Fund;

- Global Macro Hedge Fund;

- Managed Futures Hedge Fund;

- Multi-Strategy Hedge Fund;

- Credit Suisse hedge fund index.

\subsubsection{Convertible Arbitrage Hedge Fund}

Convertible arbitrage fund invests in convertible bonds and debentures of a company and simultaneously taking short position in the underlying shares. Convertible arbitrage originated because most convertible bonds were often trading at a price below their fair value. The strategy works by buying cheap convertible and to delta hedge its risks until the mispricing has disappeared. This is a dynamic process that is similar to delta hedging done by options trader throughout the day.

\subsubsection{Dedicated Short Bias Hedge Fund}

Dedicated short bias hedge fund follows a strategy to take net short position by combining long plus short positions in equities etc. Even if the returns of short bias hedge funds are lower than the index, a particular short selling strategy that earns more than the borrowing cost can be combined with a passive investment, to create a net investment that has both a higher return than the index and at much lower risk.

\subsubsection{Long/Short Equity Hedge Fund}

These hedge funds take both long and short positions primarily in equity related securities. These funds have been active in the markets for decades and constitute the fastest growing segment among alternative investment strategies. 


\subsubsection{Emerging Markets Hedge Fund}

These funds usually try to explore the opportunities in emerging markets. However, historically they have produced average returns with a high level of volatility, emerging market hedge funds have performed better than emerging market long-only indices, but not better than traditional US equities.

\subsubsection{Equity Market Neutral Hedge Fund}

These funds seek to exploit pricing inefficiencies between related equity securities. At the same time neutralizing exposure to market risk.

\subsubsection{Event Driven Hedge Fund}

These funds try to exploit the opportunity driven by company specific events. One such example is the hedge fund manager Alphonse Fletcher Jr who profited by using dividend arbitrage arising from different tax treatment in different geographies. Some other common event driven hedge funds are:

\subsubsection{Event Driven Distressed Hedge Fund}

There is a common phrase in finance world for deriving profits from distressed companies: "Dead cat bounce", and these hedge funds do the same. They focus on debt or equity of companies that are or are expected to be in financial or operational difficulty. This may involve reorganizations, bankruptcies, distressed sales and other corporate restructurings.

\subsubsection{Event Driven Multi-Strategy Hedge Fund}

These strategies include Merger arbitrage funds who invest in event-driven situations such as mergers or acquisitions, including leveraged buyouts, mergers, or hostile takeovers.

\subsubsection{Fixed Income Arbitrage Hedge Fund}

These funds use a wide spectrum of strategies that seek to exploit pricing anomalies within and across global fixed income markets.

\subsubsection{Global Macro Hedge Fund}

These funds tend to make leveraged, directional, opportunistic investments in global currency, equity, bond and commodity markets on a discretionary basis.

\subsubsection{Managed Futures Hedge Fund}

These Hedge funds trade primarily listed commodity and financial futures contracts on behalf of their clients, mostly on an algorithmic basis.

\subsubsection{Multi-Strategy Hedge Fund}

These hedge funds deploy all most any of the strategies stated above to capture the alpha. These hedge funds are usually most aggressive.

\subsubsection{Credit Suisse Hedge Fund Index}

The Credit Suisse Hedge Fund Index, an asset-weighted benchmark that seeks to measure hedge fund performance and provide the most accurate representation 
of the hedge fund universe

\section{Result and Summary Statistics}

Hedge fund returns mostly deviate from normal and are left-skewed and leptokurtic, largely due to non-linear nature of investments done by hedge funds (Table 1). This is also due to biases faced in data collection for hedge fund indexes. Further, we also observe from Table 2, that global macro hedge fund index has the highest mean return of $0.811 \%$ per month, followed by event driven distressed asset hedge fund with mean return of $0.753 \%$ per month. Comparing hedge fund indices with Dow Jones Industrial Average, hereafter referred as DJIA, we see that except global macro and event driven distressed hedge fund index, all other hedge fund indexes underperformed DJIA in terms of mean return per month.

A general timeline trend of all hedge funds indices depicts a drop in return over the period (refer to Tables 1-13, which depicts the respective hedge fund index return versus DJIA and Credit Suisse hedge fund index).

Also, if we observe that during 2008-2009 crisis, all the major hedge fund indexes witnessed big declines, close to the order of declines in DJIA, suggesting that there are no additional diversification benefits arising from investing in hedge funds vis-à-vis other asset classes. However, there are two exceptions:

1) Equity market neutral hedge fund index witnessed close to $-40 \%$ return in a month, significantly higher than DJIA and any other hedge fund indexes (Table 5), this is largely because it has a heavy left-skewness of -12.6 and is highly

Table 1. Normal return and risk characteristics of hedge funds, DJIA, credit Suisse hedge fund index.

\begin{tabular}{|c|c|c|c|c|c|c|c|c|}
\hline & Mean & StDev & Min & Median & $\operatorname{Max}$ & Skew & Kurt & \#Obs \\
\hline Credit Suisse Hedge Fund Index & $0.64 \%$ & $1.96 \%$ & $-7.55 \%$ & $0.69 \%$ & $8.53 \%$ & -0.11 & 3.41 & 288 \\
\hline DJIA & $0.74 \%$ & $4.12 \%$ & $-15.13 \%$ & $0.94 \%$ & $10.60 \%$ & -0.60 & 1.28 & 288 \\
\hline Credit Suisse Convertible Arbitrage Hedge Fund Index & $0.55 \%$ & $1.81 \%$ & $-12.59 \%$ & $0.75 \%$ & $5.81 \%$ & -2.69 & 18.55 & 288 \\
\hline Credit Suisse Dedicated Short Bias Hedge Fund Index & $-0.39 \%$ & $4.69 \%$ & $-11.28 \%$ & $-0.84 \%$ & $22.71 \%$ & 0.72 & 1.54 & 277 \\
\hline Credit Suisse Long/Short Equity Hedge Fund Index & $0.73 \%$ & $2.59 \%$ & $-11.43 \%$ & $0.78 \%$ & $13.01 \%$ & 0.01 & 4.17 & 288 \\
\hline Credit Suisse Emerging Markets Hedge Fund Index & $0.66 \%$ & $3.83 \%$ & $-23.03 \%$ & $1.02 \%$ & $16.42 \%$ & -0.81 & 6.80 & 288 \\
\hline Credit Suisse Equity Market Neutral Hedge Fund Index & $0.40 \%$ & $2.67 \%$ & $-40.45 \%$ & $0.56 \%$ & $3.66 \%$ & -12.60 & 192.30 & 288 \\
\hline Credit Suisse Event Driven Hedge Fund Index & $0.67 \%$ & $1.73 \%$ & $-11.77 \%$ & $0.92 \%$ & $4.22 \%$ & -2.04 & 9.98 & 288 \\
\hline Credit Suisse Event Driven Distressed Hedge Fund Index & $0.75 \%$ & $1.75 \%$ & $-12.45 \%$ & $0.99 \%$ & $4.15 \%$ & -2.07 & 11.64 & 288 \\
\hline Credit Suisse Event Driven Multi-Strategy Hedge Fund Index & $0.63 \%$ & $1.88 \%$ & $-11.52 \%$ & $0.84 \%$ & $4.78 \%$ & -1.61 & 6.98 & 288 \\
\hline Credit Suisse Event Driven Risk Arbitrage Hedge Fund Index & $0.48 \%$ & $1.13 \%$ & $-6.15 \%$ & $0.52 \%$ & $3.81 \%$ & -0.90 & 4.68 & 288 \\
\hline Credit Suisse Fixed Income Arbitrage Hedge Fund Index & $0.43 \%$ & $1.47 \%$ & $-14.04 \%$ & $0.64 \%$ & $4.33 \%$ & -4.79 & 38.05 & 288 \\
\hline Credit Suisse Global Macro Hedge Fund Index & $0.81 \%$ & $2.53 \%$ & $-11.55 \%$ & $0.81 \%$ & $10.60 \%$ & 0.16 & 5.05 & 288 \\
\hline Credit Suisse Managed Futures Hedge Fund Index & $0.44 \%$ & $3.30 \%$ & $-9.35 \%$ & $0.28 \%$ & $9.95 \%$ & 0.05 & -0.11 & 288 \\
\hline Credit Suisse Multi-Strategy Hedge Fund Index & $0.63 \%$ & $1.40 \%$ & $-7.35 \%$ & $0.76 \%$ & $4.28 \%$ & -1.74 & 7.22 & 285 \\
\hline
\end{tabular}


Table 2. Rank ordered mean return hedge funds, DJIA, credit Suisse hedge fund index.

\begin{tabular}{ll}
\hline \multicolumn{1}{c}{ Rank Ordered Mean Return } & Mean \\
\hline Credit Suisse Dedicated Short Bias Hedge Fund Index & $-0.391 \%$ \\
Credit Suisse Equity Market Neutral Hedge Fund Index & $0.403 \%$ \\
Credit Suisse Fixed Income Arbitrage Hedge Fund Index & $0.433 \%$ \\
Credit Suisse Managed Futures Hedge Fund Index & $0.441 \%$ \\
Credit Suisse Event Driven Risk Arbitrage Hedge Fund Index & $0.477 \%$ \\
Credit Suisse Convertible Arbitrage Hedge Fund Index & $0.552 \%$ \\
Credit Suisse Event Driven Multi-Strategy Hedge Fund Index & $0.627 \%$ \\
Credit Suisse Multi-Strategy Hedge Fund Index & $0.629 \%$ \\
Credit Suisse Hedge Fund Index & $0.641 \%$ \\
Credit Suisse Emerging Markets Hedge Fund Index & $0.656 \%$ \\
Credit Suisse Event Driven Hedge Fund Index & $0.666 \%$ \\
Credit Suisse Long/Short Equity Hedge Fund Index & $0.732 \%$ \\
DJIA & $0.742 \%$ \\
Credit Suisse Event Driven Distressed Hedge Fund Index & $0.753 \%$ \\
Credit Suisse Global Macro Hedge Fund Index & $0.811 \%$ \\
\hline
\end{tabular}

leptokurtic with kurtosis equal to 192.3. This significant deviation from normal distribution for equity market neutral hedge fund is due to the investing strategy of the hedge fund comprising this index, who exploit pricing inefficiencies between related equity securities, which can often give very high negative return in case of a crisis situation.

2) Dedicated short bias hedge fund index (Table 2) witnessed a monthly return high of 9.7\% during 2008-09 crisis, while DJIA was at one time down by $14.1 \%$ in a month. Dedicated short bias hedge fund has a right skewness of 0.723 and is platykurtic with kurtosis of 1.54 , which is less than 3 . These statistical variables are different that all other hedge fund index because of the investment style in dedicated short bias hedge fund, where in the fund short-sells an overvalued stock, making them even more profitable during a bear market or a crisis situation. As a result, we do see additional diversification benefit arising from investing in dedicated short bias hedge funds vis-à-vis other asset classes.

\subsection{Risk Adjusted Performance Measures of Hedge Funds, DJIA, Credit Suisse Hedge Fund İndex}

Hedge fund exposed to several forms of risks. As a result, it becomes necessary to evaluate their risk adjusted performance. Following are the three major risk taken by hedge funds: 1) market risk or systemic risk, a special feature of hedge funds industry is the heavy use of leverage, that can multiply the market risk by manifolds, 2) credit risk faced by hedge funds, due to exposure to counter party and, 3) liquidity risk, arising from redemption requests and investment in illiquid 
assets.

Depending on the hedge fund strategy, these risks can impact different hedge fund indices in a different way. A dedicates short bias hedge fund or long/short hedge fund is exposed to the risk of "short squeeze". One recent example is that of Pershing square capital management, which faced a severe short squeeze on Herbalife. Other hedge funds like M\&A arbitrage hedge fund are subject to event risk, Emerging Markets hedge funds are subject to sovereign risk.

Analysing the performance of hedge fund indices only on the basis of return is not sufficient. To better understand the performance of various hedge fund indices, we will analyse the return of hedge funds after adjusting for these risk. So, we will now comment on various risk-adjusted measures, analysis from it and their limitations.

\subsection{A Sharpe Ratio}

The Sharpe ratio is a good indicator of average return earned over risk free rate, for a hedge fund. Sharpe ratio is defined by following formula:

$$
\text { Sharpe } \text { Ratio }_{i, t}=\frac{R_{i, t}-R_{f, t}}{\sigma_{t}}
$$

Here, the $R_{i, t}$ represents the average monthly returns of hedge fund index $i$ during the last 36 months and $R_{f, t}$ represents the monthly risk free rate at the end of month $t$. An illustration of how this calculation is done is shown in Tables 3-5. For analysis we have taken risk free rate in U.S. as benchmark.

Table 3. Sharpe ratio hedge fund indices, DJIA credit suisse hedge fund index.

\begin{tabular}{lc}
\hline \multicolumn{1}{c}{ Sharpe Ratio } & Full Sample (Jan 94 to Dec 17) \\
\hline Credit Suisse Hedge Fund Index & 0.214 \\
DJIA & 0.139 \\
Convertible Arbitrage Hedge Fund Index & 0.194 \\
Dedicated Short Bias Hedge Fund Index & -0.176 \\
Long/Short Equity Hedge Fund Index & 0.193 \\
Emerging Markets Hedge Fund Index & 0.172 \\
Equity Market Neutral Hedge Fund Index & 0.229 \\
Event Driven Hedge Fund Index & 0.271 \\
Event Driven Distressed Hedge Fund Index & 0.345 \\
Event Driven Multi-Strategy Hedge Fund Index & 0.214 \\
Event Driven Risk Arbitrage Hedge Fund Index & 0.171 \\
Fixed Income Arbitrage Hedge Fund Index & 0.263 \\
Global Macro Hedge Fund Index & 0.279 \\
Managed Futures Hedge Fund Index & 0.039 \\
Multi-Strategy Hedge Fund Index & 0.340 \\
\hline
\end{tabular}


Table 4. Risk and return statistics and sharpe ratio of hedge funds, DJIA, credit Suisse hedge fund index.

\begin{tabular}{cccccc}
\hline $\begin{array}{c}\text { Credit Suisse Event Driven } \\
\text { Distressed Hedge Fund Index }\end{array}$ & $\begin{array}{c}\text { StDev } \\
(\mathrm{T} 36 \mathrm{M})\end{array}$ & $\begin{array}{c}\text { Average Return } \\
(\mathrm{T} 36 \mathrm{M})\end{array}$ & $\mathbf{R f}$ & $\mathbf{R f}(1 \mathrm{M})$ & $\begin{array}{c}\text { Sharpe } \\
\text { Ratio }\end{array}$ \\
\hline $12 / 29 / 2017$ & $0.920 \%$ & $0.220 \%$ & $2.405 \%$ & $0.198 \%$ & 0.0238037 \\
$12 / 31 / 2014$ & $1.105 \%$ & $0.800 \%$ & $2.170 \%$ & $0.179 \%$ & 0.5622163 \\
$12 / 31 / 2011$ & $1.828 \%$ & $0.698 \%$ & $1.876 \%$ & $0.155 \%$ & 0.2969403 \\
$12 / 31 / 2008$ & $2.082 \%$ & $0.010 \%$ & $2.220 \%$ & $0.183 \%$ & -0.0831394 \\
$12 / 31 / 2005$ & $0.854 \%$ & $1.346 \%$ & $4.399 \%$ & $0.359 \%$ & 1.1558409 \\
$12 / 31 / 2002$ & $1.642 \%$ & $0.555 \%$ & $3.818 \%$ & $0.313 \%$ & 0.1478796 \\
$12 / 31 / 1999$ & $2.696 \%$ & $1.076 \%$ & $6.435 \%$ & $0.521 \%$ & 0.2056929 \\
$12 / 31 / 1996$ & $1.760 \%$ & $1.319 \%$ & $6.430 \%$ & $0.521 \%$ & 0.4532915 \\
$12 / 31 / 1993$ & & & & & \\
Average & & $0.753 \%$ & & & 0.3453157 \\
\hline
\end{tabular}

Table 5. Risk statistics of hedge fund indices, DJIA credit suisse hedge fund index.

\begin{tabular}{cccccc}
\hline $\begin{array}{c}\text { Credit Suisse Dedicated Short } \\
\text { Bias Hedge Fund Index }\end{array}$ & $\begin{array}{c}\text { StDev } \\
(\mathrm{T} 36 \mathrm{M})\end{array}$ & $\begin{array}{c}\text { Average Return } \\
(\mathrm{T} 36 \mathrm{M})\end{array}$ & $\mathbf{R f}$ & Rf (1M) & $\begin{array}{c}\text { Sharpe } \\
\text { Ratio }\end{array}$ \\
\hline $12 / 29 / 2017$ & $4.463 \%$ & $-0.669 \%$ & $2.405 \%$ & $0.198 \%$ & -0.1942306 \\
$12 / 31 / 2014$ & $3.196 \%$ & $-1.529 \%$ & $2.170 \%$ & $0.179 \%$ & -0.5343669 \\
$12 / 31 / 2011$ & $4.853 \%$ & $-1.276 \%$ & $1.876 \%$ & $0.155 \%$ & -0.2949307 \\
$12 / 31 / 2008$ & $4.489 \%$ & $0.455 \%$ & $2.220 \%$ & $0.183 \%$ & 0.0604990 \\
$12 / 31 / 2005$ & $3.904 \%$ & $-0.805 \%$ & $4.399 \%$ & $0.359 \%$ & -0.2981581 \\
$12 / 31 / 2002$ & $5.534 \%$ & $0.919 \%$ & $3.818 \%$ & $0.313 \%$ & 0.1095096 \\
$12 / 31 / 1999$ & $6.144 \%$ & $-0.410 \%$ & $6.435 \%$ & $0.521 \%$ & -0.1515864 \\
$12 / 31 / 1996$ & $4.113 \%$ & $0.099 \%$ & $6.430 \%$ & $0.521 \%$ & -0.1024462 \\
$12 / 31 / 1993$ & & & & & \\
Average & & $-0.402 \%$ & & & -0.1757137 \\
\hline
\end{tabular}

A greater Sharpe ratio indicates higher excess return for per unit of volatility. In Table 6, we see that the highest Sharpe ratio is 0.345 and it belongs to Event Driven Distressed Hedge Fund Index. It can be interpreted as event driven distressed hedge fund index generates almost 35 basis points excess returns per unit of standard deviation, on an average. It has the second highest mean return, while global macro hedge fund has the highest mean return and the third highest Sharpe ratio, this finding is alone sufficient to conclude that risk adjustment is necessary to obtain meaningful comparison between hedge fund indices. We can also see that dedicated short bias hedge fund index has the lowest Sharpe ratio of -0.176 , which is not surprising as it also has the lowest mean return of $-0.39 \%$. Two other index that has lowest Sharpe ratios are managed futures hedge fund index (0.039) and event driven risk arbitrage hedge fund index (0.171). 
Table 6. Rank ordered sharpe ratio hedge fund indices, DJIA credit suisse hedge fund index.

\begin{tabular}{lc}
\hline \multicolumn{1}{c}{ Rank ordered Sharpe ratio } & Full Sample \\
\hline Credit Suisse Dedicated Short Bias Hedge Fund Index & -0.175714 \\
Credit Suisse Managed Futures Hedge Fund Index & 0.039158 \\
DJIA & 0.138895 \\
Credit Suisse Event Driven Risk Arbitrage Hedge Fund Index & 0.170850 \\
Credit Suisse Emerging Markets Hedge Fund Index & 0.171598 \\
Credit Suisse Long/Short Equity Hedge Fund Index & 0.193017 \\
Credit Suisse Convertible Arbitrage Hedge Fund Index & 0.193849 \\
Credit Suisse Hedge Fund Index & 0.213587 \\
Credit Suisse Event Driven Multi-Strategy Hedge Fund Index & 0.214183 \\
Credit Suisse Equity Market Neutral Hedge Fund Index & 0.229475 \\
Credit Suisse Fixed Income Arbitrage Hedge Fund Index & 0.263084 \\
Credit Suisse Event Driven Hedge Fund Index & 0.271359 \\
Credit Suisse Global Macro Hedge Fund Index & 0.279161 \\
Credit Suisse Multi-Strategy Hedge Fund Index & 0.339626 \\
Credit Suisse Event Driven Distressed Hedge Fund Index & 0.345316 \\
\hline
\end{tabular}

They are also ranked in the bottom five in terms of mean return. However, equity neutral hedge fund index, has the sixth highest Sharpe ratio but has second the lowest mean return, reinforcing the importance of risk-adjusted returns.

Comparing hedge fund indices with DJIA (Table 6), we see that except dedicated short bias and managed futures hedge fund, and all other hedge fund indices have outperformed the DJIA, in terms of Sharpe ratio. However, in terms of mean returns DJIA was the third best, only after Global Macro and Event driven hedge fund index. Further, Credit Suisse hedge fund index, which is a composite of all the hedge fund strategies, lies exactly in the middle in terms of Sharpe ratio and has outperformed DJIA (Table 6).

\subsection{B Sortino Ratio}

We know that standard deviation does not differentiate between favourable and unfavourable returns. However, we also know from our analysis that most hedge fund indices have a high degree of left skewness and are leptokurtic. This is driven by non-linear investment strategy of hedge funds, leaving a significant tail-risk, which can lead to severe losses during market down turn. To account for these tail risks, we will use the concept of downside risk. As per Bali, and Demirtas [7] [8] trading strategies of hedge funds including leverage, short-selling and derivatives, create significant non-normality in distribution of return. As a result, we need to use some more measure to analyze hedge fund returns other than traditional measures of return analysis. 
The first such ratio that we will use is Sortino Ratio. Sortino ratio is similar to Sharpe ratio, with two changes: 1) one can replace the risk free rate with minimum acceptable rate of return; 2) volatility in the denominator is replaced by semi-deviation of returns.

We have used monthly risk free rate in the U.S. as benchmark. Further, we calculated semi-deviation for each hedge fund index $i$ for month $t$ using the following formula:

$$
\begin{aligned}
& \text { Semi-Deviation }_{i, t}=\frac{1}{36} \sqrt{\sum_{T=t-36}^{t-1} d_{i, T}^{2}} \\
& d_{i, T}= \begin{cases}R_{i, T}-R_{f, T} & \text { if } R_{i, T}<R_{f, T} \\
0 & \text { if } R_{i, T}>R_{f, T}\end{cases}
\end{aligned}
$$

Using these semi-deviations, we calculate Sortino ratio for each hedge fund index $i$ for month $t$, using:

$$
\text { Sortino } \text { Ratio }_{i, t}=\frac{R_{i, t}-R_{f, t}}{\text { Semi-Deviation }_{i, t}}
$$

where, $R_{i, t}$ denotes the return of hedge fund index $i$ during month $t$ and $R_{f, t}$ denotes the risk-free rate at the end of month $t$. Using this we arrive at sortino ratio for each month and take the average sortino ratio from 31st December 1996 to December 2017 to arrive at values as indicated in Table 7. An illustration of how we arrived at these Sortino ratios is shown in Table 8.

Table 7. Sortino ratio hedge fund indices, DJIA credit suisse hedge fund index.

\begin{tabular}{lc}
\hline \multicolumn{1}{c}{ Sortino Ratio } & Full Sample \\
\hline Credit Suisse Hedge Fund Index & 2.306078 \\
DJIA & 1.057055 \\
Credit Suisse Convertible Arbitrage Hedge Fund Index & 1.556642 \\
Credit Suisse Dedicated Short Bias Hedge Fund Index & -1.158568 \\
Credit Suisse Long/Short Equity Hedge Fund Index & 2.186166 \\
Credit Suisse Emerging Markets Hedge Fund Index & 1.673219 \\
Credit Suisse Equity Market Neutral Hedge Fund Index & 4.380551 \\
Credit Suisse Event Driven Hedge Fund Index & 3.249322 \\
Credit Suisse Event Driven Distressed Hedge Fund Index & 5.252875 \\
Credit Suisse Event Driven Multi-Strategy Hedge Fund Index & 2.450133 \\
Credit Suisse Event Driven Risk Arbitrage Hedge Fund Index & 1.028543 \\
Credit Suisse Fixed Income Arbitrage Hedge Fund Index & 2.157023 \\
Credit Suisse Global Macro Hedge Fund Index & 4.154314 \\
Credit Suisse Managed Futures Hedge Fund Index & 0.442917 \\
Credit Suisse Multi-Strategy Hedge Fund Index & 3.792850 \\
\hline
\end{tabular}


Table 8. Risk statistics and sortino ratio hedge fund indices, DJIA credit suisse hedge fund index.

\begin{tabular}{cccccccc}
\hline $\begin{array}{c}\text { Credit Suisse Event Driven } \\
\text { Distressed Hedge Fund Index }\end{array}$ & $\boldsymbol{R}_{\boldsymbol{f}}$ & $\boldsymbol{R}_{\boldsymbol{f}}(\mathbf{M})$ & $\begin{array}{c}\text { Monthly } \\
\text { Return }\end{array}$ & $d_{i, t}$ & $d_{(i, t)}^{2}$ & $\begin{array}{c}\text { Semi } \\
\text { Deviation }\end{array}$ & $\begin{array}{c}\text { Sortino Ratio } \\
\text { Sortino Ratio }\end{array}$ \\
\hline $29 / 12 / 17$ & $2.405 \%$ & $0.198 \%$ & $1.52 \%$ & $0.00 \%$ & $0.000 \%$ & $0.111 \%$ & 11.89718105 \\
$30 / 11 / 17$ & $2.415 \%$ & $0.199 \%$ & $-0.38 \%$ & $0.58 \%$ & $0.003 \%$ & $0.112 \%$ & -5.168997777 \\
$31 / 10 / 17$ & $2.377 \%$ & $0.196 \%$ & $0.53 \%$ & $0.00 \%$ & $0.000 \%$ & $0.111 \%$ & 3.010091334 \\
$29 / 09 / 17$ & $2.339 \%$ & $0.193 \%$ & $0.69 \%$ & $0.00 \%$ & $0.000 \%$ & $0.126 \%$ & 3.953804913 \\
\hline $31 / 03 / 97$ & & & & Calculation Continued Till 31/12/96 & -0.190608225 \\
$28 / 02 / 97$ & $6.720 \%$ & $0.543 \%$ & $0.52 \%$ & $0.02 \%$ & $0.000 \%$ & $0.125 \%$ & -1.389514811 \\
$31 / 01 / 97$ & $6.907 \%$ & $0.558 \%$ & $0.38 \%$ & $0.18 \%$ & $0.000 \%$ & $0.130 \%$ & 11.1633067 \\
$31 / 12 / 96$ & $6.556 \%$ & $0.531 \%$ & $2.16 \%$ & $0.00 \%$ & $0.000 \%$ & $0.146 \%$ & 12.85528782 \\
\hline
\end{tabular}

A higher Sortino ratio indicates that the hedge fund index has generated higher excess return per unit of downside risk.

The highest sortino ratio is for Event driven distressed asset hedge fund index (5.25), which is not surprising as it was also the highest in terms of Sharpe ratio and the second highest in terms of mean return. However, we see a moderate shift in the ranking of equity market neutral hedge fund; it is ranked second in terms of sortino ratio of 4.38, while it was sixth in terms of Sharpe ratio and second last in terms of mean return. Further, global macro hedge fund index maintains its third ranking in terms of sortino ratio of 4.15 , it was earlier ranked third in terms of Sharpe ratio too. Global macro hedge fund was however ranked first in terms of mean returns.

In terms of performance, dedicated short bias hedge fund index is ranked last with sortino ratio of -1.16 , which is not surprising it has the lowest mean return and lowest Sharpe ratio too. Managed futures hedge fund index is ranked second last with sortino ratio of 0.44 , which is also not surprising as it also has the second last Sharpe ratio. Our findings tend to be similar to that of Eling and Schuhmacher [15], who indicated that despite deviation of hedge fund returns from normal distribution, the comparison between Sharpe ratio and other performance measures tends to be similar.

In terms of comparison with equity markets, DJIA has sortino ratio higher than only, dedicated short biased, managed futures and event driven risk arbitrage hedge fund. All other hedge fund indices outperformed DJIA in terms of sortino ratio (Table 9).

\subsection{Calmar Ratio}

As indicated by the study of Dichev and Yu the return to a hedge fund investor is also dependent upon the entry exit timing and exit timing for an investor. 
Table 9. Rank ordered sortino ratio hedge fund indices, DJIA credit suisse hedge fund index.

\begin{tabular}{lc}
\hline \multicolumn{1}{c}{ Rank Ordered Sortino Ratio } & Full Sample \\
\hline Credit Suisse Dedicated Short Bias Hedge Fund Index & -1.158568 \\
Credit Suisse Managed Futures Hedge Fund Index & 0.442917 \\
Credit Suisse Event Driven Risk Arbitrage Hedge Fund Index & 1.028543 \\
DJIA & 1.057055 \\
Credit Suisse Convertible Arbitrage Hedge Fund Index & 1.556642 \\
Credit Suisse Emerging Markets Hedge Fund Index & 1.673219 \\
Credit Suisse Fixed Income Arbitrage Hedge Fund Index & 2.157023 \\
Credit Suisse Long/Short Equity Hedge Fund Index & 2.186166 \\
Credit Suisse Hedge Fund Index & 2.306078 \\
Credit Suisse Event Driven Multi-Strategy Hedge Fund Index & 2.450133 \\
Credit Suisse Event Driven Hedge Fund Index & 3.249322 \\
Credit Suisse Multi-Strategy Hedge Fund Index & 3.792850 \\
Credit Suisse Global Macro Hedge Fund Index & 4.154314 \\
Credit Suisse Equity Market Neutral Hedge Fund Index & 4.380551 \\
Credit Suisse Event Driven Distressed Hedge Fund Index & 5.252875 \\
\hline
\end{tabular}

Linking this understanding, we will be trying to capture the most common risk in hedge fund industry: drawdown. It reflects the percentage fall in the value of an asset or index during a historic time frame. Drawdown is linked to the entry and exit timing for investors in hedge fund as it can be linked to behavioural psychology aspect of regret of not selling an asset class or redeeming from hedge fund, when it was at its peak.

We calculate, maximum drawdown as:

$$
\text { Maximum Drawdown } n_{i, t}=\frac{\left(\text { Maximum } N A V_{T 36 M}-{\text { Minimum } \left.N A V_{T 36 M}\right)}_{\text {Maximum } N A V_{T 36 M}}\right.}{\text { Dax }} \times 100
$$

where, Maximum Drawdown ${ }_{i, t}$ indicates maximum drawdown for hedge fund index $i$ for month $t$. Maximum $N A V_{T 36 M}$ indicates maximum value of net asset value of hedge fund index $i$ during the last 36 months. Minimum $N A V_{T 36 M}$ indicates minimum value of net asset value of hedge fund index $i$ during the last 36 months.

We did this for each month and calculated maximum drawdown for each month. Then we calculated Calmar ratio using:

$$
\text { Calmer Ratio }_{i, t}=\frac{R_{i, t}}{\text { Maximum Drawdown }_{i, t}}
$$

where, $R_{i, t}$ indicates monthly return for hedge fund index $i$ during month $t$. And Calmer Ratio $_{i, t}$ indicates Calmar ratio for hedge fund index $i$ during month $t$. 
After calculating the Calmar ratio for the full sample (January 1996 to December 2017) we take the average value to arrive at the Calmar ratio for hedge fund i. Table 11 gives an example of calculating Calmar ratio.

The long/short equity hedge fund index has the highest Calmar ratio of 0.031, while it was ranked 8th and 10th respectively in terms of sortino and Sharpe ratio, which is a significant move in ranking. It can be interpreted as least regret of

Table 10. Calmar ratio hedge fund indices, DJIA credit suisse hedge fund index.

\begin{tabular}{lc}
\hline \multicolumn{1}{c}{ Calmar Ratio } & Full Sample \\
\hline Credit Suisse Hedge Fund Index & 0.027806 \\
DJIA & 0.017794 \\
Credit Suisse Convertible Arbitrage Hedge Fund Index & 0.025030 \\
Credit Suisse Dedicated Short Bias Hedge Fund Index & -0.011580 \\
Credit Suisse Long/Short Equity Hedge Fund Index & 0.031346 \\
Credit Suisse Emerging Markets Hedge Fund Index & 0.024810 \\
Credit Suisse Equity Market Neutral Hedge Fund Index & 0.020735 \\
Credit Suisse Event Driven Hedge Fund Index & 0.026027 \\
Credit Suisse Event Driven Distressed Hedge Fund Index & 0.026283 \\
Credit Suisse Event Driven Multi-Strategy Hedge Fund Index & 0.025754 \\
Credit Suisse Event Driven Risk Arbitrage Hedge Fund Index & 0.029537 \\
Credit Suisse Fixed Income Arbitrage Hedge Fund Index & 0.020732 \\
Credit Suisse Global Macro Hedge Fund Index & 0.027349 \\
Credit Suisse Managed Futures Hedge Fund Index & 0.020541 \\
Credit Suisse Multi-Strategy Hedge Fund Index & 0.027391 \\
\hline
\end{tabular}

Table 11. Risk statistics and calmar ratio hedge fund indices, DJIA credit suisse hedge fund index.

\begin{tabular}{ccccccc}
\hline $\begin{array}{c}\text { Credit Suisse Long/Short } \\
\text { Equity Hedge Fund Index }\end{array}$ & Min T36 & Max T36 & $\begin{array}{c}\text { Maximum } \\
\text { Drawdown }\end{array}$ & $\begin{array}{c}\text { Monthly } \\
\text { Return }\end{array}$ & $\begin{array}{c}\text { Calmar } \\
\text { Ratio }\end{array}$ & $\begin{array}{c}\text { Average } \\
\text { Calmar Ratio }\end{array}$ \\
\hline $29 / 12 / 17$ & 643.37 & 741.83 & $13.273 \%$ & $0.83 \%$ & 0.06 & 0.0313 \\
$30 / 11 / 17$ & 643.37 & 735.70 & $12.550 \%$ & $0.36 \%$ & 0.03 & \\
$31 / 10 / 17$ & 643.37 & 733.03 & $12.231 \%$ & $2.05 \%$ & 0.17 & \\
$29 / 09 / 17$ & 639.71 & 718.31 & $10.942 \%$ & $0.24 \%$ & 0.02 & \\
$31 / 08 / 17$ & 639.67 & 716.56 & $10.730 \%$ & $0.83 \%$ & 0.08 & \\
& & Calculation Continued till 31/12/1996 & \\
$30 / 04 / 97$ & 91.22 & 137.04 & $33.435 \%$ & $0.01 \%$ & 0.00 & \\
$31 / 03 / 97$ & 91.22 & 137.04 & $33.435 \%$ & $-2.27 \%$ & -0.07 & \\
$28 / 02 / 97$ & 91.22 & 137.04 & $33.435 \%$ & $-1.58 \%$ & -0.05 & \\
$31 / 01 / 97$ & 91.22 & 137.04 & $33.435 \%$ & $3.49 \%$ & 0.10 & \\
$31 / 12 / 96$ & 91.22 & 132.42 & $31.113 \%$ & $0.82 \%$ & 0.03 & \\
\hline
\end{tabular}


not selling at the peak. Similar argument can support the second ranking of even driven risk arbitrage (Calmar ratio: 0.0295), which was ranked 13th and 12th respectively in terms of sortino and Sharpe ratio.

Further, dedicated short bias hedge fund continues to be ranked the last with a Calmar ratio of -0.0115 . Two, other hedge fund index, which showed significant move in ranking as per Calmar ratio are: event driven distressed hedge fund index and equity market neutral hedge fund index. Event driven distressed hedge fund index has a Calmar ratio of 0.0263 and is ranked 6, while it was ranked 1st in case of both sortino and Sharpe ratio, indicating a relatively higher regret of not selling at the peak. Also, equity market neutral hedge fund index has a Calmar ratio of 0.0207 and is ranked 11th, while it was ranked 2nd and 6th in terms of Sortino and Sharpe ratio, respectively, indicating a relatively higher regret of not selling at the peak. The hedge fund index, which earlier showed good ranking in Sharpe and sortino ratio, while showing poor ranking in Calmar ratio are more exposed to the liquidity risk, arising from redemption. Apart from the expectation mentioned above all other hedge fund indexes showed less than 2 spot changes in ranking, affirming the study of Eling and Schuhmacher, who indicated that despite deviation of hedge fund returns from normal distribution, the comparison between Sharpe ratio and other performance measures tends to be similar.

In terms of comparison with equity markets, DJIA has Calmar ratio of 0.0177 , which is only higher than dedicated short biased hedge fund. All other hedge fund indices have outperformed the DJIA with respect to Calmar ratio. Further,

Table 12. Rank ordered calmar ratio.

\begin{tabular}{|c|c|}
\hline Rank Ordered Calmar Ratio & Full Sample \\
\hline Credit Suisse Dedicated Short Bias Hedge Fund Index & -0.011579 \\
\hline DJIA & 0.017794 \\
\hline Credit Suisse Managed Futures Hedge Fund Index & 0.020541 \\
\hline Credit Suisse Fixed Income Arbitrage Hedge Fund Index & 0.020732 \\
\hline Credit Suisse Equity Market Neutral Hedge Fund Index & 0.020735 \\
\hline Credit Suisse Emerging Markets Hedge Fund Index & 0.024810 \\
\hline Credit Suisse Convertible Arbitrage Hedge Fund Index & 0.025030 \\
\hline Credit Suisse Event Driven Multi-Strategy Hedge Fund Index & 0.025754 \\
\hline Credit Suisse Event Driven Hedge Fund Index & 0.026027 \\
\hline Credit Suisse Event Driven Distressed Hedge Fund Index & 0.026283 \\
\hline Credit Suisse Global Macro Hedge Fund Index & 0.027349 \\
\hline Credit Suisse Multi-Strategy Hedge Fund Index & 0.027391 \\
\hline Credit Suisse Hedge Fund Index & 0.027806 \\
\hline Credit Suisse Event Driven Risk Arbitrage Hedge Fund Index & 0.029537 \\
\hline Credit Suisse Long/Short Equity Hedge Fund Index & 0.031346 \\
\hline
\end{tabular}


Table 13. Sharpe, sortino and calmar ratio hedge fund indices, DJIA credit suisse hedge fund index.

\begin{tabular}{lccc}
\hline \multicolumn{1}{c}{ Ranking } & $\begin{array}{c}\text { Sharpe } \\
\text { Ratio }\end{array}$ & $\begin{array}{c}\text { Sortino } \\
\text { Ratio }\end{array}$ & $\begin{array}{c}\text { Calmar } \\
\text { Ratio }\end{array}$ \\
\hline Credit Suisse Dedicated Short Bias Hedge Fund Index & 15 & 15 & 15 \\
DJIA & 13 & 12 & 14 \\
Credit Suisse Managed Futures Hedge Fund Index & 14 & 14 & 13 \\
Credit Suisse Fixed Income Arbitrage Hedge Fund Index & 5 & 9 & 12 \\
Credit Suisse Equity Market Neutral Hedge Fund Index & 6 & 2 & 11 \\
Credit Suisse Emerging Markets Hedge Fund Index & 11 & 10 & 10 \\
Credit Suisse Convertible Arbitrage Hedge Fund Index & 9 & 11 & 9 \\
Credit Suisse Event Driven Multi-Strategy Hedge Fund Index & 7 & 6 & 8 \\
Credit Suisse Event Driven Hedge Fund Index & 4 & 5 & 7 \\
Credit Suisse Event Driven Distressed Hedge Fund Index & 1 & 1 & 6 \\
Credit Suisse Global Macro Hedge Fund Index & 3 & 3 & 5 \\
Credit Suisse Multi-Strategy Hedge Fund Index & 2 & 4 & 4 \\
Credit Suisse Hedge Fund Index & 8 & 7 & 3 \\
Credit Suisse Event Driven Risk Arbitrage Hedge Fund Index & 12 & 13 & 2 \\
Credit Suisse Long/Short Equity Hedge Fund Index & 10 & 8 & 1 \\
\hline
\end{tabular}

Credit Suisse hedge fund index, which is a composite of all hedge fund strategies, has a Calmar ratio of 0.0278 and is ranked 3rd, indicating a relatively low liquidity risk arising from redemption.

\section{Conclusions}

It is observed that hedge fund index returns deviate from normal distribution as they have a high degree of left skewness and leptokurtosis, with exception of dedicated short bias hedge fund, which has right-skewness and platy kurtosis. The deviation from normal distribution is driven by non-linearity, which is inherent in the investment strategy of hedge funds. By analyzing the mean return per month of hedge fund indexes we observe two things: (i) Most hedge fund indices witness a drop in returns over time; (ii) most hedge funds, excluding dedicated short bias hedge fund, do not provide additional diversification benefits with respect to traditional asset class, as they witness big declines in their performance in crisis period, and the worst decline is witnessed by equity market neutral hedge fund index.

Given the deviation of hedge fund index data from normal, different risk measures were used like standard deviation, semi-deviation and drawdown to adequately understand various dimensions of investment risk and performance among themselves and with broader equity markets. Following major results emerge from our analysis: 1) on a risk-adjusted basis, majority of hedge fund indices out-perform the broader equity market; 2) ranking of various hedge fund 
strategies, does not changes drastically with use of different risk-adjusted measures (Table 13);3) as opposed to prevalent studies like Atilgan, Bali and Demirtas [6], indicating Equity market neutral hedge fund index as the best performer in terms of risk-adjusted returns, the current study finds Event driven distressed hedge fund Index as the best performer. 4) we also observe that event driven distressed hedge fund index and equity market neutral hedge fund index, despite having one of the best sortino and Sharpe ratio, indicating that these two hedge fund types are exposed to the liquidity risk, arising from redemptions. The liquidity risk arising from redemption also happens to explain $-40 \%$ return for equity market hedge fund index during 2008-09 crisis, as many of its component hedge funds might have faced severe redemption pressure, 5) Calmar ratio for Credit Suisse hedge fund index, which is a composite of all hedge fund strategies, is 0.0278 and is ranked 3rd, significantly higher than even DJIA (ranked second last) indicating that mutual funds can face higher redemption pressure than hedge fund during crisis situations, which is also supported by relatively difficult entry and exit conditions in hedge fund over the mutual funds, and, 6) However, we do see ETF's coming for various hedge fund strategy, which can reduce the entry and exit conditions, which can increase the redemption pressure on hedge funds.

The study focused on select hedge funds and was able to analyze the expected risk-adjusted return along with drawdown. Further, the study can be extended by comparing the risk-adjusted return on hedge funds with mutual funds, cryptocurrency hedge funds.

\section{Conflicts of Interest}

The authors declare no conflicts of interest regarding the publication of this paper.

\section{References}

[1] Atil, Y., Bali, T. and Demirtas, K. (2013) The Performance of Hedge Fund Indices. Borsa Istanbul Review, 13, 30-52. https://doi.org/10.1016/j.bir.2013.10.007

[2] Bali, T.G., Brown, S. and Demirtas, K.O. (2013) Do Hedge Funds Outperform Stocks and Bonds? Management Science, 58, 1887-1903. https://doi.org/10.1287/mnsc.1120.1689

[3] Ackermann, C., McNealy, R. and Ravenscraft, D. (1999) The Performance of Hedge Funds: Risk, Return, and Incentives. The Journal of Finance, 54, 833-874. https://doi.org/10.1111/0022-1082.00129

[4] Huang, Y.S. Chen, C.R. and Kato, I. (2017) Different Strokes by Different Folks: The Dynamics of Hedge Fund Systematic Risk Exposure and Performance. International Review of Economics \& Finance, 48, 367-388. https://doi.org/10.1016/j.iref.2017.01.001

[5] Hwang, I., Xu, S., In, F. and Kim, T.S. (2017) Systemic Risk and Cross-Sectional Hedge Fund Returns. Journal of Empirical Finance, 42, 109-130. https://doi.org/10.1016/j.jempfin.2017.03.002

[6] Brown, S.J., Goetzmann, W.N. and Sungil Park, J.M. (2001) Careers and Survival: 
Competition and Risk in the Hedge Fund and CTA Industry. The Journal of Finance, 56, 1869-1886. https://doi.org/10.1111/0022-1082.00392

[7] Fung, W.K.H. and Hsieh, D.A. (1997) Empirical Characteristics of Dynamic Trading Strategies: The Case of Hedge Funds. The Review of Financial Studies, 10, 275-230.https://doi.org/10.1093/rfs/10.2.275

[8] Fung, W.K.H. and Hsieh, D.A. (2001) The Risk in Hedge Fund Strategies: Theory and Evidence From Trend Followers. The Review of Financial Studies, 14, 313-341.

[9] Schneeweis, T. and Spurgin, R. (1998) Mutlifactor Analysis of Hedge Fund, Managed Futures, and Mutual Fund Return and Risk Characteristics. The Journal of Alternative Investments, 1, 1-24. https://doi.org/10.3905/jai.1998.407852

[10] Lhabitant, F.-S. (2004) Hedge Funds: Quantitative Insights. Wiley, Hoboken, NJ. https://doi.org/10.1002/9781118673546

[11] Brown, S.J., Goetzmann, W., Ibbotson, R.G. and Ross, S.A. (1992) Survivorship Bias in Performance Studies. The Review of Financial Studies, 5, 553-580. https://doi.org/10.1093/rfs/5.4.553

[12] Ardia, D. and Boudt, K. (2018) The Peer Performance Ratios of Hedge Funds. Journal of Banking \& Finance, 87, 351-368. https://doi.org/10.1016/j.jbankfin.2017.10.014

[13] Cheng, T.T., Cai, B.Q. and Yan, C. (2018) Time-Varying Skills (versus Luck) in U.S. Active Mutual Funds and Hedge Funds. Journal of Empirical Finance, 49, 81-106.

[14] Lo, A.W. (2008) Hedge Funds, Systemic Risk, and the Financial Crisis of 2007-2008: Written Testimony for the House Oversight Committee Hearing on Hedge Funds. https://ssrn.com/abstract=1301217 https://doi.org/10.2139/ssrn.1301217

[15] Kim, J.-M. (2016) Failure Risk and the Cross-Section of Hedge Fund Returns. Financial Management, 45, 845-876. https://doi.org/10.1111/fima.12101

[16] Zheng, Y., Osmer, E. and Zhang, R. (2018) Sentiment Hedging: How Hedge Funds Adjust Their Exposure to Market Sentiment. Journal of Banking \& Finance, 88, 147-160. https://doi.org/10.1016/j.jbankfin.2017.11.016

[17] Frydenberg, S., Hrafnkelsson, K., Bromseth, V.S. and Westgaard, S. (2017) Hedge Fund Strategies and Time-Varying Alphas and Betas. Journal of Wealth Management, 19, 44-60. https://doi.org/10.3905/jwm.2017.19.4.044

[18] Schmidhuber, C. and Moix, P. (2001) Fat Tail Risk: The Case for Hedge Funds (Part I). AIMA Newsletter, 48, 29-31.

[19] Molyboga, M., Baek, S. and Bilson, J.F.O. (2017) Assessing Hedge Fund Performance with Institutional Constraints: Evidence from CTA Funds. Journal of Asset Management, 18, 547-565. https://doi.org/10.1057/s41260-017-0053-8

[20] Mitchell, M. and Pulvino, T. (2001) Characteristics of Risk and Return in Risk Arbitrage. The Journal of Finance, 56, 2135-2175.

https://doi.org/10.1111/0022-1082.00401

[21] Agarwal, V. and Naik, N.Y. (2004) Risks and Portfolio Decisions Involving Hedge Funds. Review of Financial Studies, 17, 63-98. https://doi.org/10.1093/rfs/hhg044

[22] Agarwal, V., Eser Arisoy, Y. and Naik, N.Y. (2017) Volatility of Aggregate Volatility and Hedge Fund Returns. Journal of Financial Economics, 125, 491-510. https://doi.org/10.1016/j.jfineco.2017.06.015

[23] Sharpe, W.F. (1992) Asset Allocation: Management Style and Performance Measurement. The Journal of Portfolio Management, 18, 7-19.

https://doi.org/10.3905/jpm.1992.409394 
[24] Treynor, J.L. and Black, F. (1973) How to Use Security Analysis to Improve Portfolio Selection. Journal of Business, 46, 66-88. https://doi.org/10.1086/295508

[25] Magdon-Ismail, M., Atiya, A.F., Pratap, A. and Abu-Mostafa, Y.S. (2004) On the Maximum Drawdown of a Brownian Motion. Journal of Applied Probability, 41, 147-161. https://doi.org/10.1239/jap/1077134674

[26] Sortino, F.A., van der Meer, R. and Plantinga, A. (1999) The Dutch Triangle. The Journal of Portfolio Management, 26, 50-58. https://doi.org/10.3905/jpm.1999.319775

[27] Sortino, F.A. and van der Meer, R. (1991) Downside Risk. Journal of Portfolio Management, 17, 27-31. https://doi.org/10.3905/jpm.1991.409343

[28] Jagannathan, R., Malakhov, A. and Novikov, D. (2010) Do Hot Hands Exist among Hedge Fund Managers? An Empirical Evaluation. Journal of Finance, 65, 217-255. https://doi.org/10.1111/j.1540-6261.2009.01528.x

[29] Liang, B. (2000) Hedge Funds: The Living and the Dead. Journal of Financial and Quantitative Analysis, 35, 309-326. https://doi.org/10.2307/2676206

[30] Amin, G.S. and Kat, H.M. (2003) Hedge Fund Performance 1990-2000: Do the Money Machines Really Add Value? Journal of Financial and Quantitative Analysis, 38, 251-274. https://doi.org/10.2307/4126750

[31] Dichev, I. and Yu, G. (2011) Higher Risk, Lower Returns: What Hedge Fund Investors Really Earn. Journal of Financial Economics, 100, 248-263.

https://doi.org/10.1016/j.jfineco.2011.01.003

[32] Aragon, G.O. (2007) Share Restrictions and Asset Pricing: Evidence from the Hedge Fund Industry. Journal of Financial Economics, 83, 33-58.

https://doi.org/10.1016/j.jfineco.2005.11.001

[33] Aragon, G.O. and Martin, J.S. (2012) A Unique View of Hedge Fund Derivatives Usage: Safeguard or Speculation. Journal of Financial Economics, 105, 436-456. https://doi.org/10.1016/j.jfineco.2012.02.004

[34] Sun, Z., Wang, A.W. and Zheng, L. (2018) Only Winners in Tough Times Repeat: Hedge Fund Performance Persistence over Different Market Conditions. Journal of Financial and Quantitative Analysis, 53, 2199-2225. https://doi.org/10.1017/S0022109018000200

[35] Agarwal, V., Green, T.C. and Ren, H.L. (2018) Alpha or Beta in the Eye of the Beholder: What Drives Hedge Fund Flows? Journal of Financial Economics, 127, 417-434. https://doi.org/10.1016/j.jfineco.2018.01.006 